\title{
We are what we eat: Ensuring safe and healthy food in the 21st century
}

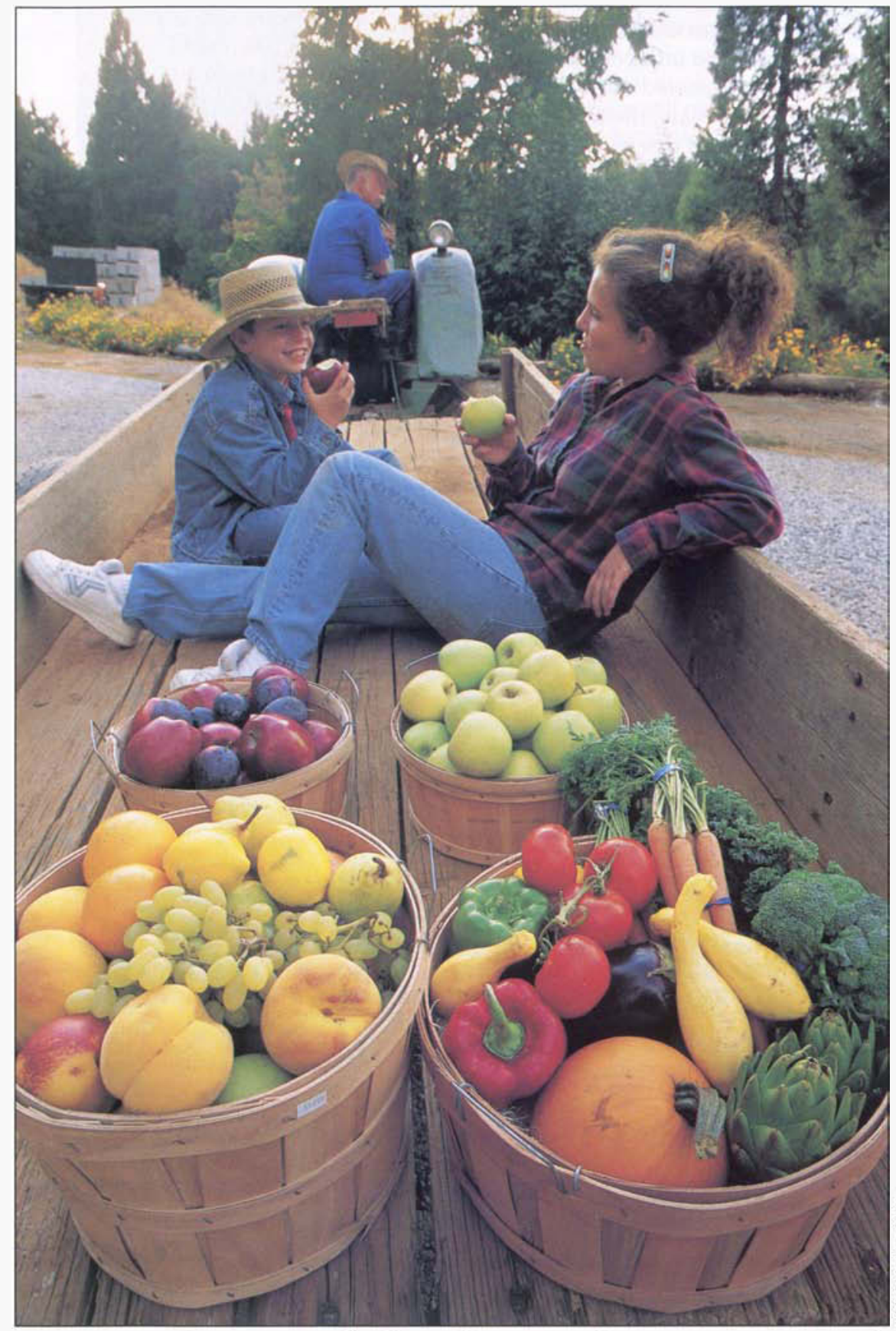

Foodborne illnesses can have severe economic and political ramifications. All the cider mills in Apple Hill, in the Sierra foothills around Camino, are participating in a proactive quality assurance plan to prevent contamination of their fresh, unpasteurized apple juice and cider. At Kids, Inc. ranch, Peter and Christine Delfino enjoy the fruits of their family's farm.
Carl Keen

Chair, Department of Nutrition, UC Davis

\section{Bennie Osburn \\ Dean, School of Veterinary Medicine, UC Davis}

A lthough there is an abundance of food in to occur here and around the globe. The current population of over 5.5 billion people will increase to 8 billion in the next quarter-century. In California alone, the population is expected to increase by 15 million people in the next 20 to 25 years. The growing need for food production in our state comes at the same time that prime farmland is being converted to housing and businesses (see p. 47). The implications of these dramatic increases in population and land required for food production will require that food be produced by the global community. The major food suppliers of the future may well be a relatively few multinational companies that will dictate the sources, quality and quantity of foods that we eat in this new century.

Previous issues of the California Agriculture special series, "Future in Focus: 2000-2025," have addressed the impact of demographic change (January-February 2000), environmental and natural resource problems (March-April 2000) and agricultural technology and sustainability (July-August 2000). This issue addresses food security and the challenges we face to provide a high-quality food source that is safe and nutritious.

\section{Nutrition and health}

As we enter the 21st century, there is the expectation by many that changing one's diet can markedly reduce the risk for a multitude of diseases including diabetes, cardiovascular disease, macular degeneration, osteoporosis and senile dementia. In addition, many expect that modest changes in diet will translate into improvements in cognition, mood, physical performance and general well-being. While the hypothesis that certain changes in the diet will influence physical states is a reasonable one, the probability that all of these benefits can be achieved simultaneously by diet is very low. 
Nutrient-disease interactions. Specific dietary recommendations are not cure-alls. While the investigation of dietary factors that can influence one's risk for the development of certain diseases will be an exciting area of research for decades to come, progress in this area is likely to be slow. First, for most diseases we still have only a poor understanding of the actual biochemical mechanisms that contribute to their occurrence and advancement. In the absence of this information, well-focused investigations on nutrient-disease interactions are difficult to construct. Further confounding the situation is the lack of good biomarkers for most diseases, or for that matter, nutritional status! As a consequence, dietary intervention studies are often shaped by epidemiological observations that identify associative rather than causative factors.

Furthermore, while epidemiological studies can provide interesting clues regarding nutrition and health, numerous questions remain. For example, a wealth of epidemiological studies suggest that diets rich in fruits and vegetables are associated with a reduced risk for certain cancers (see p. 26). However, the identity of the compounds present in these foods that are responsible for protective effects has remained elusive. The identification of phytonutrients and the quantification of the amounts needed in the diet to provide optimal protection presents an important research challenge for the next decade (see p. 33).

Genetics. A second major issue that will delay progress is that an individual's genetic background can have a profound effect on their susceptibility to a number of diseases and their response to dietary manipulations. As a consequence, it is difficult at present to identify the correct population in which a study should be conducted. Further, dietary recommendations may differ considerably depending on one's genetic constitution. These unknowns will also provide significant challenges to public-health officials involved with food delivery programs.

Although numerous challenges must be addressed in the area of nutrition and health, we have made important strides in this field during the last decade and are poised for rapid progress in many areas (see pages 12 , 19,26 and 33).

Armed with a better understanding of the protectant nutrients in food, we will be able to turn attention to the development of new foods, and food products that increase the delivery of important nutrients. This will be a demanding task that will take the concerted action of university scientists, food industry partners and government agencies. However, the ultimate reward will be the creation of a diet that may markedly enhance the quality of life for all.

\section{Food safety}

The economic and political implications of a safe food supply have been underestimated until recently. The most dramatic recent example of a foodborne problem with major negative repercussions has been bovine spongiform encephalopathy (BSE), known as "mad cow" disease, which afflicted cattle in the United Kingdom (England, Scotland, Wales and Ireland) in epidemic proportions starting in the mid-1980s. This problem was followed by the appearance of a new variant of CreutzfeldtJakob disease (CJD), chiefly in British young people who consumed contaminated beef, with the first human fatality reported in 1996. Both of these diseases are associated with an agent thought to be derived from affected cattle, which causes a fatal nervous-system disorder. There is no known treatment.

Initially, more than 150,000 cattle were affected by eating contaminated animal-protein feed supplements. Then 80 people became infected with the agent by eating the contaminated beef. This large loss of cattle and the human fatalities have had severe adverse economic and political ramifications in Britain, and have resulted in significant changes in what people eat. Economically, the losses from cattle slaughtered, trade restrictions, bankruptcies and devaluation of land prices have cost the United Kingdom over $\$ 5$ billion. Consumption of beef has declined dramatically from what it was 15 years ago, further affecting farm livelihoods. Politically, the British Conservative Party lost the parliamentary elections in 1997, in large part because its members downplayed the importance of this foodborne disease problem. Even though the number of deaths from the new variant of CJD is low so far, projections indicate an additional 136,000 deaths from the disease could occur over the next 60 years.

Worldwide, there are 1.5 billion cases of foodborne illness each year; these illnesses rank among the most common forms of disease in the world. More than 3 million deaths are recorded per year. As many as 300,000 individuals have been affected in a single outbreak. A
Nutritionists and government agencies have recommended major dietary changes. However, our understanding of nutrient-disease interactions is still limited.

\section{Although it has often been stated that the United States has the safest food supply in the world, the fact that one out of four citizens suffers from foodborne illness in a given year is significant.}




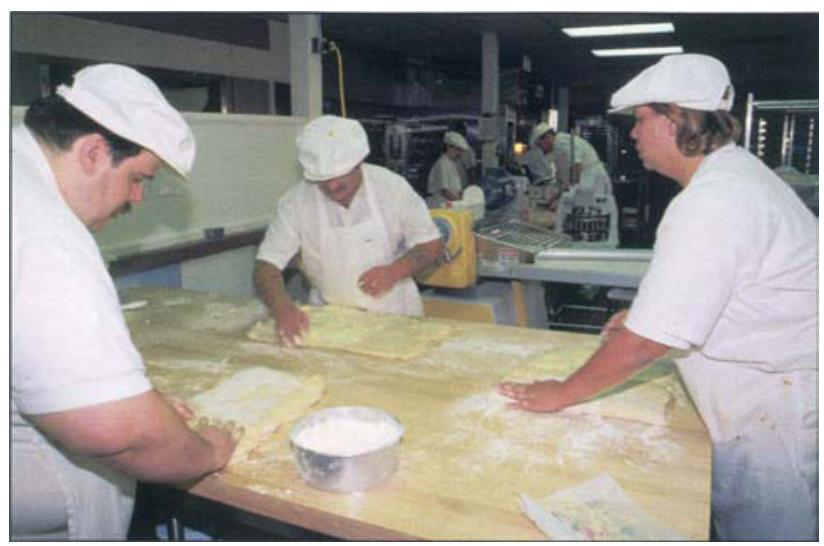

Food preparation and handling can have an impact on safety. At the Northern California Food Service and Baking School in Butte County, workers are trained in the art of specialty bread baking. a given year is significant. variety of diseasecausing organisms are involved. In the last 25 years, at least 30 newly recognized infectious agents have been associated with $\frac{\frac{9}{5}}{\pi}$ food-and waterborne illnesses (see pages 62, 69 and 78). In the United States, the Centers for Disease Control and Prevention reports 76 million cases, 325,000 hospitalizations and 5,000 deaths per year. Although it has often been stated that the United States has the safest food supply in the world, the fact that one out of four citizens suffers from foodborne illness in

Globalization of the food supply. For a variety of reasons, including loss of agricultural lands, increased labor and production costs, and year-round consumer demand for fresh fruits and vegetables, agricultural products are being brought into the United States and Europe on a larger scale each year (see p. 54). These products are raised in environments where microbial agents new to the United States may be introduced with imported food. This represents another way for foreign microorganisms to become established in this country. Also, standards for chemical use in production in many countries are different than those practiced in the United States. These potential contaminants are significant risk factors for consumers.

More complex processing, transport, storage and preparation. Central processing operations create efficiencies but can amplify foodborne disease, affecting large quantities of product. Widespread distribution systems can move products - and food- and waterborne pathogens - more quickly than ever. The increase in consumption of foods prepared outside the home are of concern as proper handling, appropriate storage temperatures and final preparation add "critical control points" and potential risks in the food chain.

Recommended dietary changes. Major changes in eating habits, being encouraged by nutritionists and government agencies to reduce the risks of cancer and heart disease, have resulted in an increase of foodborne disease. For example, the eating of uncooked fresh fruits and vegetables has resulted in greatly increased foodborne illnesses. Over the past 10 years, California Department of Health Services records indicate that an increasingly greater percentage $(36 \%)$ of the outbreaks were associated with fresh fruits and vegetables. These are foods that may not be suitable for cooking and therefore pose a greater risk of harboring microbial causes of disease.

Natural/organic foods and supplements. Interest in natural organic foods and supplements continues to increase (see pages 26,33 ). Herbal products sometimes may include poisonous plant extracts that have powerful toxins affecting organs such as the liver, kidneys and heart, causing serious health problems. Organic foods, like all uncooked produce, may contain contaminants that cause foodborne illnesses. Oversight of natural and organic products will help assure safer products for consumers.

Emerging pathogens. The ability of microbes to exchange genetic information - including disease-causing traits and antibiotic resistance - is now well known. The exchange of disease-causing genetic material helps innocuous microbes become virulent. Nonpathogens can become pathogens or develop antibiotic resistance through gene transfer. These new agents affect not only the digestive system but other organs as well. Serious, chronic health problems may follow certain food-and waterborne illnesses, including arthritis, kidney failure and degenerative neurological disease. In addition to the challenges of identifying new pathogens, antibiotic-resistance factors exchanged between microbes make it more difficult to treat many bacterial infections in people and animals.

Genetically modified food products. Another issue of major concern is the genetically modified crops and animals that are being developed. Many benefits are associated with the modifications; however, the long-term health impacts on people and animals are not yet known. Many GMO foods have not received thorough testing to determine whether they cause allergies or create nutritional or metabolic imbalances. Consumer acceptance will depend on assurances of safe products.

Food safety infrastructure. Probably the biggest challenge is the increasing difficulty that existing regulatory infrastructures have in handling food safety issues; there are more than a dozen U.S. agencies that claim a role in food safety. Unprepared for rapid changes in food production systems and new issues in foodborne disease, officials have been slow to communicate with each other and respond to change. Current agencies are burdened with bureaucracy, making it more difficult to establish criteria or monitor the increasingly complex food chain. Since there is no single agency to set 
priorities for much-needed research, such programs are severely underfunded. These issues are further complicated by the rapid changes in agriculture, globalization issues (including trade restrictions and liberalization of regulations), and the control of foods by multinational corporations from farm to table.

There is a way to bring us to an effective solution to this growing problem. It is time for a new, comprehensive California agency that includes all the broad aspects of the food chain. The regulation umbrella must encompass both animal- and plant-based foods. Such an organization would have the clout to oversee critical issues such as the safety of genetically modified food products. This agency needs to be empowered to carry out coordinated surveillance and diagnostic testing. Setting up an efficient system for reporting and responding to foodborne outbreaks would be another priority. Finally, to assure the quality of foods and consumer health - as well as animal and environmental health such an agency would guide credible research and testing programs.

We should begin with a major food-safety forum to lay these issues out on the table in a new way. Such a forum would recommend to our policy-makers a new structure addressing all aspects of food production safety, integrated monitoring of food products and public health, and assurance of the public health "from farm to fork." This bold move would establish California again as a leader in setting world standards for food safety.

\section{Science briefs}

\section{Supplements may contain high doses}

Although they may protect against some forms of cancer when consumed in the diet, plant flavonoids may actually have the capacity to become carcinogenic at higher levels, scientists at the UC Berkeley School of Public Health report in a new study.

In the August Free Radical Biology and Medicine, UC Berkeley toxicologist Martyn Smith and graduate student Christine F. Skibola describe the many biological activities of flavonoids, showing that high levels of plant flavonoids can bind with and damage chromosomes and DNA in cell cultures. The effects follow a gradient, with protective effects at low levels and mutagenic effects at high levels.

The authors point out that no one could swallow in food anywhere near the amounts of flavonoids provided in some dietary supplements. In fact, Asians and vegetarians have less cancer than other people, in part because of their high consumption of flavonoids in soy, green tea and vegetables (see pages 26, 33).

Studies in the United States, Europe and Asia, for instance, show that people get 5 to 68 milligrams of the flavonoid quercetin in their diets per day. But a popular health food supplement recommends taking 1,000 milligrams in one swallow - 10 to 20 times more than even a high dietary intake of quercetin.

"That's when we get worried," says Skibola. "There is no rhyme or reason for the dosages recommended on these bottles. These com- pounds need to be regulated." Products such as Gingko biloba pills, grape-seed extract and flaxseed may contain high levels of flavonoids.

\section{UC hosts food security symposium}

The Community Food Security Symposium UC's first conference to explore the relationships among agriculture, hunger and communitybased food systems - took place Oct. 10 and 11 at UC Berkeley. "I'm particularly pleased that many of the Division's programs are working closely with the community to develop innovative approaches to these critical issues," says UC Vice President Reg Gomes.

The purpose of the symposium was to share information among the University, government agencies and community groups, in order to develop community-based solutions, with agriculture as a critical link. The UC Food Security Workgroup, which organized the symposium, includes UC Cooperative Extension, UC Sustainable Agriculture Research and Education Program (SAREP) and USDA.

Symposium participants discussed programs linking small farmers with school lunch programs; community gardening projects; farmers' markets and food stamps; and hunger in lowincome communities (see pages 8, 10, 40, 47).

"UC can help consumers understand the benefits of nutritious, locally produced food, which in turn helps create markets for small farmers," says Gail Feenstra, UC SAREP food systems analyst.

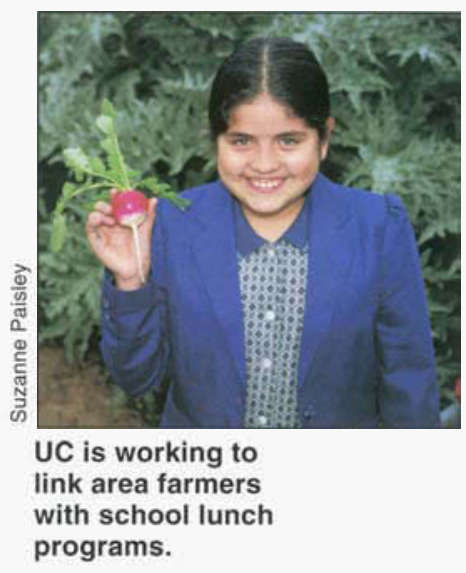

